\title{
Gestão Estratégica da Energia Nucleoelétrica no Brasil: Recursos e Competências Críticos para seu Sucesso
}

\author{
T. Diana L. v. A. Macedo-Soares \\ Luiz Augusto P. A. Figueira
}

\begin{abstract}
RESUMO
Desde 1996, o setor elétrico brasileiro tem sofrido transformações em sua estrutura básica. Porém ainda há muito que fazer, por estar a matriz energética concentrada em uma só fonte, a hidráulica. Este artigo tem como objetivo propor um arcabouço analítico com as competências e os recursos fundamentais à gestão estratégica da exploração da energia nucleoelétrica no país. Compartilha os resultados de um estudo de caso da Eletrobrás Termonuclear - Eletronuclear, complementado por uma investigação documental de quatro outras empresas: duas geradoras brasileiras, Furnas e Chesf; e duas geradoras internacionais de energia núcleoelétrica, Exelon e Tvo. Para o estudo de caso, os dados foram coletados de várias fontes e com diferentes meios: investigação documental/telematizada e dois levantamentos de percepções, com auxílio de questionário estruturado e entrevistas. Utilizouse o método AHP, Analytic Hierarchy Process, para hierarquizar as categorias de recursos e competências identificadas, segundo a percepção dos participantes da pesquisa. Os resultados evidenciaram a ausência de um modelo de comercialização da energia nucleoelétrica no Brasil. Adicionalmente, proporcionaram subsídios para construir o arcabouço analítico em exame e formular ações mais efetivas para seu desenvolvimento, considerando todos os stakeholders.
\end{abstract}

Palavras-chave: estratégia; competências; energia nuclear; resource-based view; AHP - Analytic Hierarchy Process.

\begin{abstract}
Since 1996, the Brazilian electric sector's basic structure has undergone significant changes. Still, a lot has to be done, however, considering that the energetic matrix is basically concentrated upon a single source - the hydraulic. The objective of this article is to propose an analytic framework with the fundamental resources and competencies for managing effectively the exploration of nuclearelectric energy in Brazil. It shares the results of an in-depth case study of Eletronuclear - Brazil's state-owned nuclear energy producer - complemented by documentary investigations on the resources and competencies of four other firms (two energy producing firms in Brazil, Chesf and Furnas, and two international nucleoelectric energy producing firms, Exelon and Tvo). For the case study, data were collected by way of different means: documental / telematic investigations, and two surveys of management perceptions. Utilizing the Analytic Hierarchy Process method, the different groups of resources and competencies identified were classified in terms of priority, according to managerial perceptions. The results highlighted the lack of a model to commercialize nuclear-electric energy in Brazil. Additionally, they provided the necessary elements to construct the analytic framework at issue, and to formulate more effective actions for its development, considering all stakeholders.
\end{abstract}

Key words: strategy; competencies; nuclear energy; resource-based view; Analytic Hierarchy Process. 


\section{INTRODUÇÃO}

Em 2001, com o racionamento de energia, o setor elétrico, no Brasil, viveu uma de suas maiores crises e trouxe à discussão a necessidade de diversificar as fontes de energia elétrica, procurando alternativas, notadamente as fontes de energia renováveis, além das fontes de energia térmica, tais como o carvão, o óleo diesel e a energia nucleoelétrica. Atualmente, somente a Eletrobrás Termonuclear - Eletronuclear, única empresa brasileira de geração de energia térmica baseada na tecnologia nuclear, está autorizada a produzir energia nucleoelétrica no país. Segundo o plano decenal da Eletrobrás, que engloba o período 2000-2009, dos 67682 MW que se espera gerar de energia elétrica, apenas $2,9 \%$ corresponde à fonte nuclear e menos de $1 \%$ a outras fontes alternativas. Em termos de produção mundial, a energia nuclear contribui com $14 \%$ da produção de eletricidade. No Brasil, em 2003, esse percentual restringiuse a 2,0\%. Esses números sugerem um pequeno interesse no desenvolvimento da tecnologia nuclear por parte do país, o que, inicialmente, parece contraditório, em função da necessidade de diversificar a matriz energética e da demanda existente.

Considerando o atual contexto, o objetivo deste artigo é apresentar os resultados da análise estratégica da Eletronuclear dentro de uma perspectiva integrativa sistêmica, que procurou responder à seguinte pergunta: No caso de uma empresa, como a Eletronuclear, de geração de energia nucleoelétrica no país, quais os recursos e as competências necessários e desejáveis para explorar as oportunidades e reduzir as ameaças constituídas pelos fatores macroambientais e pelos demais atores estratégicos, com vistas a proporcionar um desempenho operacional e financeiro satisfatório que atenda a todos os stakeholders (partes interessadas)?

Para responder a essa pergunta adotaram-se os seguintes passos: i) caracterização da estratégia adotada pela empresa; ii) avaliação das implicações estratégicas dos fatores macroambientais e dos atores-chave, ao desempenharem seus papéis, em termos de constituírem oportunidades e ameaças, reais e potenciais; iii) avaliação das implicações estratégicas dos fatores organizacionais (recursos, incluindo competências e condições para adquirir e gerenciá-los) em termos de constituírem forças e fraquezas, reais e potenciais; iv) levando em conta o desempenho da Eletronuclear, avaliação da estratégia da empresa em termos de sua capacidade de capitalizar as forças constituídas pelos recursos e competências da empresa e condições organizacionais necessárias para alavancálos, reduzindo as fraquezas, de modo a efetivamente explorar as oportunidades e 
neutralizar as possíveis ameaças criadas pelo macroambiente; v) identificação dos fatores organizacionais de outras empresas geradoras de energia nucleoelétrica no mundo e de energia predominantemente hidroelétrica no Brasil, que contribuem de maneira significativa para um desempenho satisfatório dessas organizações e poderiam também contribuir para uma empresa de geração de energia nucleoelétrica nacional; vi) consolidação dos recursos e das competências das outras geradoras pesquisadas que, somados aos que a empresa atualmente detém, são considerados pelos executivos da organização necessários e desejáveis para a efetividade da estratégia da Eletronuclear; viii) priorização das dimensões de recursos e de competências que mais contribuem à efetividade da estratégia organizacional da Eletronuclear.

A relevância dessa investigação reside em três aspectos fundamentais. Primeiro, diante da crise energética ocorrida em 2001, é fundamental para o Brasil não permanecer dependente de uma única fonte de energia. A energia nucleoelétrica, tal como as outras fontes de energia, constitui-se em uma possibilidade viável, como já ocorre em vários outros países. Em segundo lugar, no novo modelo que se tem pensado para o setor elétrico, há outras fontes de energia na natureza que, tal como a nucleoelétrica, concorrem por espaço dentro da matriz energética nacional. Assim, é importante que, mesmo numa empresa monopolista como a Eletronuclear se adotem estratégias organizacionais que garantam a produção a um preço competitivo o bastante para enfrentar a concorrência das outras diferentes fontes de energia e atender, de modo satisfatório, às necessidades de todas as partes interessadas, notadamente os acionistas, os consumidores e a comunidade em geral.

Finalmente, a exploração de outras fontes de energia, em especial a energia nucleoelétrica, traz consigo algumas dualidades. Por um lado, trata-se de fonte de energia limpa e compatível com a perspectiva de desenvolvimento sustentável; por outro, gera preocupação ambiental permanente, suscitando questões polêmicas quanto à responsabilidade ética e social inerente ao uso dessa fonte de energia.

Este artigo está estruturado em quatro partes, além desta introdução. Nas primeira e na segunda, explicam-se o referencial teórico e a metodologia. $\mathrm{Na}$ terceira parte, apresentam-se os resultados do estudo de caso. Na quarta, com auxílio do referencial teórico e à luz das limitações dos métodos adotados, os principais resultados são discutidos e consolidados a fim de obter o arcabouço analítico de recursos e competências necessários e desejáveis para geração de energia nucleoelétrica no Brasil. Por fim, avaliam-se as contribuições da pesquisa para o setor elétrico e fazem-se recomendações para futuras pesquisas. 


\section{Referencial Teórico}

\section{Conceitos Gerais}

Primeiramente, cabe esclarecer quais definições foram adotadas para os conceitos centrais da pesquisa. No caso de estratégia, baseou-se na definição de Grant (1998, p. 3), ampliada, posteriormente, por Macedo-Soares (2000), que a considera como

um propósito que dá coerência e direção às ações e decisões de uma organização, especialmente para alavancar e alocar os recursos/competências necessários para melhorar e sustentar sua performance de acordo com a visão e os objetivos da organização, tendo em vista as condições do ambiente interno e externo.

Fundamentando-se, em parte, em Van der Heijen (1996), partiu-se da premissa de que a análise estratégica implica uma série de avaliações coerente com o princípio de adequação estratégica (Hofer \& Schendel, 1978). De acordo com esse princípio, a efetividade da estratégia requer consistência entre todos os fatores estrategicamente significativos, tanto os organizacionais, quanto os macroambientais. Justificam-se, assim, as avaliações mencionadas na introdução, quando se descrevem os passos adotados na pesquisa para responder à sua questão central.

O termo competência empregado na pesquisa possui um sentido ampliado, isto é, engloba também as capacitações/habilidades no sentido de subcompetências da organização. Assim, de acordo com Day, Reibstein e Gunther (1997, p. 69), competências "constituem-se em um conjunto complexo de habilidades e conhecimentos, exercitados por meio de processos organizacionais que permitem que uma empresa coordene atividades, utilize seus ativos, aprenda e se aperfeiçoe continuamente". Parte-se da proposta de Vollmann (1996), com sua classificação de competências em distintiva, essencial, rotineira e terceirizada, para caracterizar as competências pertinentes à administração de empresas em ambiente competitivo. A partir dessa proposta, estabelece-se um paralelo para o ambiente não competitivo, com vistas a classificar as competências contidas no arcabouço final proposto, como desejáveis e necessárias. Assim, competência desejável é aquela que provê à organização meios para implementar, de forma bem sucedida, sua estratégia organizacional. Sem essa competência, a organização até poderá atingir seus objetivos, mas não de maneira efetiva. Já a competência necessária é aquela que todas as empresas, não necessariamente concorrentes no mesmo mercado, devem ter para atingir os objetivos propostos em sua estratégia. Sem essa competência, a organização dificilmente atingirá os objetivos contidos em sua estratégia. O termo competência dinâmica, empregado na pesquisa, foi inspirado a partir das definições de Day et al. (1997), Teece, Pisano e Shuen 
(1997) e Zollo e Winter (2002) e refere-se a um conjunto complexo de habilidades e conhecimentos, aprendido e assimilado, pelo qual a organização sistematicamente constrói e reconfigura seus recursos e competências em busca de uma maior efetividade.

Para caracterizar a estratégia, utilizou-se a tipologia de Mintzberg (1998), que amplia o conceito original de Porter (1980), quando considera subtipos de diferenciação (preço, imagem, suporte, qualidade e projeto), além do escopo (amplo ou restrito) e da própria não-diferenciação.

Figura 1: Modelo GI para Análise Estratégica de uma Empresa de Geração de Energia Nucleoelétrica

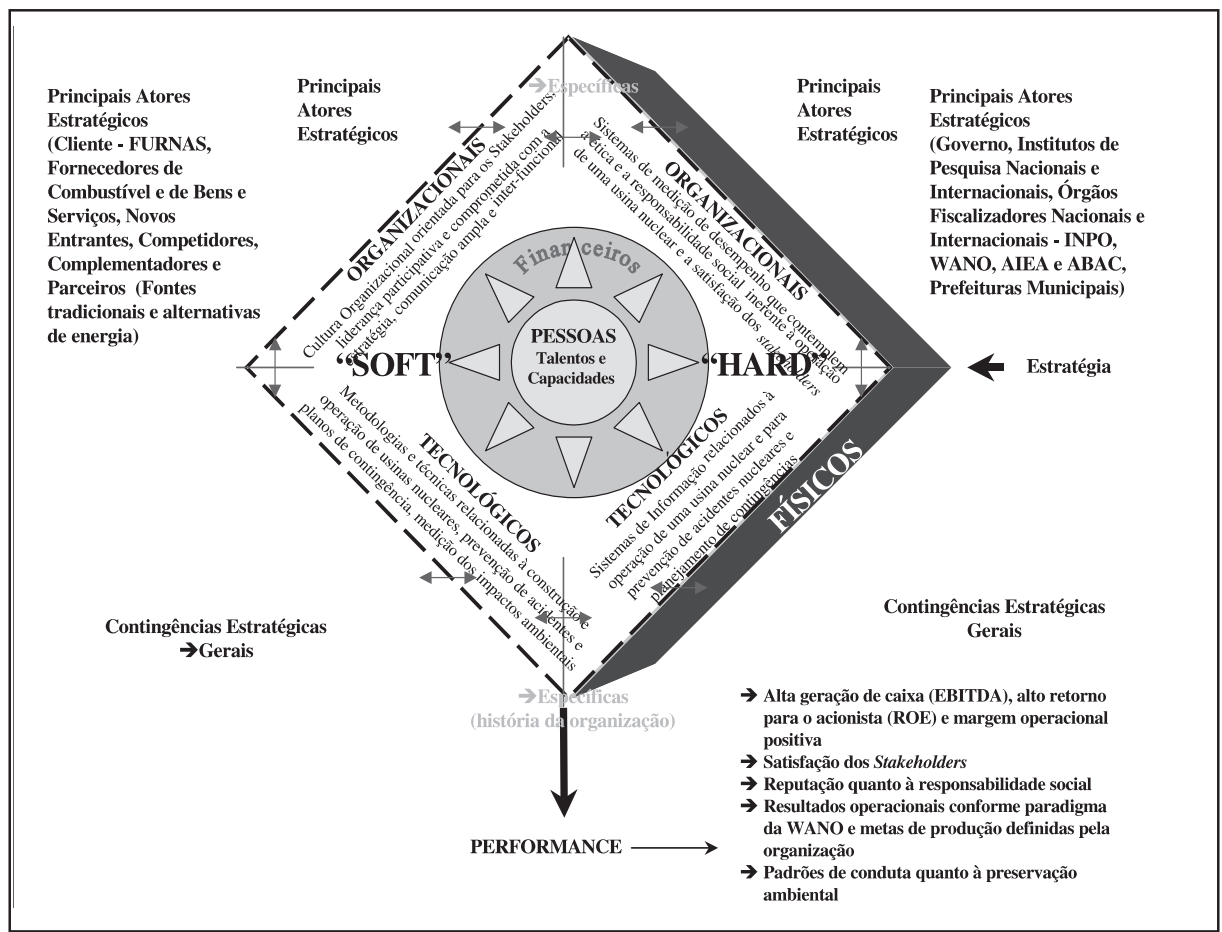

Fonte: Figueira e Macedo-Soares, 2003, p. 1176 e Figueira, 2004, p. 56.

Adicionalmente, com o objetivo de descrever, com maior precisão, o conteúdo da estratégia, assim como o processo de sua formulação e implementação, utilizaram-se os constructos de Fahey e Randall (1998), em especial quanto ao escopo (produto / serviço, cliente, geográfico, vertical e stakeholders), à sua diferenciação competitiva ou à postura (características do produto ou serviço fundamentais à distinção do produto, segundo a ótica do cliente) e às metas da organização, de acordo com a 'intenção estratégica', 'missão' ou 'visão', sejam elas explícitas ou não. 


\section{Modelo Genérico Integrativo}

Considerando a grande quantidade de fatores interagentes (internos e externos) de uma empresa de geração de energia, a avaliação da adequação estratégica deve partir de uma visão ampliada. Assim, optou-se pelo arcabouço conceitual de Macedo-Soares (2000) para a análise da adequação estratégica da Eletronuclear que adota uma perspectiva integrativa sistêmica. $\mathrm{O}$ arcabouço em exame evoluiu de uma série de modelos tradicionais (Macedo-Soares \& Chamone, 1994; MacedoSoares \& Lucas, 1996) para auxiliar análises estratégicas em várias organizações no país. Tais modelos basearam-se inicialmente em princípios da escola sociotécnica (Cherns, 1976), nos trabalhos de Child (1987), Nadler, Gerstein, Shaw e Associates (1992) e Sjölander (1985). Incorporaram-se, gradualmente, constructos de Austin (1990), Brandenburger e Nalebuff (1997), Porter (1980) e da escola 'resourcebased' (Rumelt, Schendel, \& Teece, 1991; Wernerfelt, 1984), resultando um arcabouço analítico genérico integrativo, nomeado modelo GI.

No modelo GI, a forma da empresa sugere um sistema aberto em equilíbrio para enfatizar a importância da congruência entre os fatores organizacionais e os fatores macroambientais interagentes, bem como os atores estratégicos, de acordo com o princípio de adequação estratégica. A Figura 1 retrata uma adaptação do modelo GI para uma empresa de geração de energia nucleoelétrica. Nele, os fatores organizacionais (recursos e condições de utilização desses recursos) incluem não somente ativos físicos e financeiros, mas também as capacitações/ habilidades (subcompetências) e competências. Esses fatores, considerados como variáveis principais independentes por serem controláveis, classificam-se em cinco categorias: 1) pessoais; 2) financeiros; 3) físicos; 4) organizacionais; 5) tecnológicos. Os fatores organizacionais e tecnológicos recebem ainda uma categorização adicional (hard e soft) para diferenciar as variáveis estabelecidas formalmente pela organização (hard) daquelas constituídas de uma maneira informal (soft). Ainda com relação aos fatores organizacionais, as competências são classificadas como desejáveis e necessárias. Essa classificação permite inferir a existência de ambigüidade causal, ou seja, certa dificuldade de entender como os recursos/competências de uma determinada empresa contribuem para a manutenção de sua vantagem competitiva (Diericks \& Cool, 1989).

Os fatores macroambientais são considerados variáveis secundárias, uma vez que suas implicações, positivas ou negativas, não são controláveis; apenas influenciam o desempenho das variáveis principais, no sentido de constituírem oportunidades ou ameaças. Inspirando-se em Austin (1990), o modelo contempla quatro categorias de fatores ambientais: econômicos, políticos, socioculturais e demográficos que, por sua vez, moldam o comportamento dos atores estratégicos. Tais atores podem também criar oportunidades e ameaças que influenciam os 
fatores macroambientais, à medida que desempenham os papéis propostos por Porter (1980) - cliente, fornecedor, rival, novo entrante, substituto, bem como o de 'complementador' (parceiro potencial pelos recursos ou atributos complementares que ele proporciona (Brandenburger \& Nalebuff, 1997).

O desempenho constitui a categoria de variáveis principais dependentes, por ser consequiência da gestão das variáveis principais independentes (fatores organizacionais) em interação com as secundárias (atores estratégicos e fatores macroambientais interagentes).

O Quadro 1 foi construído especificamente para empresas geradoras de energia, com vistas a interpretar e analisar os dados coletados. Ela contém uma lista de atributos necessários e desejáveis para as variáveis principais independentes (fatores organizacionais) e para as variáveis principais dependentes (desempenho), no caso da implementação e gestão de uma estratégia orientada a todos os stakeholders, considerando a responsabilidade ética, social e ambiental. Para tanto adaptaram-se os quadros de referência propostos e utilizados por MacedoSoares e Lucas (1996), Macedo-Soares e Ratton (1999), Macedo-Soares (2000) e Coutinho e Macedo-Soares (2002).

Quadro 1: Lista de Atributos Necessários/Desejáveis para as Variáveis Principais Independentes, bem como as Dependentes (Desempenho), no caso da Implementação/Gestão de Estratégia Orientada para os

Stakeholders, considerando a Responsabilidade Ética, Social e Ambiental, adaptada para Empresas de Geração de Energia Nucleoelétrica

\begin{tabular}{|c|c|c|}
\hline $\begin{array}{l}\text { Categoria de } \\
\text { Variáveis } \\
\end{array}$ & Variável & Atributos Necessários/Desejáveis \\
\hline \multirow[t]{7}{*}{$\begin{array}{c}\text { Organizacional } \\
\text { Hard }\end{array}$} & Estrutura Organizacional & $\begin{array}{l}\text { Flexível, achatada, com alto grau de descentralização de } \\
\text { poder }\end{array}$ \\
\hline & $\begin{array}{l}\text { Sistemas de Medição de } \\
\text { Desempenho }\end{array}$ & $\begin{array}{l}\text { Visíveis, balanceados, abrangentes, consistentes, adaptáveis } \\
\text { às mudanças, integrando todos os subsistemas de medição, } \\
\text { incluindo medidas de desempenho, alinhados aos objetivos } \\
\text { explicitados na estratégia e que satisfaçam todos os } \\
\text { stakeholders }\end{array}$ \\
\hline & Equipes & $\begin{array}{l}\begin{array}{l}\text { Multifuncionais, interfuncionais, com alto grau de } \\
\text { empowerment }\end{array} \\
\end{array}$ \\
\hline & Processos & Documentados e interfuncionais \\
\hline & $\begin{array}{l}\text { Sistemas de } \\
\text { Reconhecimento e } \\
\text { Recompensa }\end{array}$ & $\begin{array}{l}\text { Sistema de avaliação de desempenho dos empregados e } \\
\text { remuneração, integrados com o sistema de medição de } \\
\text { desempenho geral da empresa, levando em conta o } \\
\text { comportamento ético do empregado e seu grau de } \\
\text { conscientização em relação à responsabilidade inerente à } \\
\text { operação de uma usina nuclear }\end{array}$ \\
\hline & $\begin{array}{l}\text { Sistemas Educacionais } \\
\text { (Treinamento) }\end{array}$ & $\begin{array}{l}\text { De educação continuada dos gestores e outros empregados, } \\
\text { para aquisição de competências necessárias à melhoria } \\
\text { contínua dos processos e desempenho, aquisição de novas } \\
\text { tecnologias e para aquisição de habilidades específicas do } \\
\text { pessoal operacional }\end{array}$ \\
\hline & Sistemas Gerenciais & $\begin{array}{l}\text { Integrados através dos processos interfuncionais, com uma } \\
\text { perspectiva de orientação para os stakeholders }\end{array}$ \\
\hline
\end{tabular}




\section{(continuação)}

\section{Quadro 1: Lista de Atributos Necessários/Desejáveis para as Variáveis Principais Independentes, bem como as Dependentes (Desempenho), no caso da Implementação/Gestão de Estratégia Orientada para os Stakeholders, considerando a Responsabilidade Ética, Social e Ambiental, adaptada para Empresas de Geração de Energia Nucleoelétrica}

\begin{tabular}{|c|c|c|}
\hline $\begin{array}{l}\text { Categoria de } \\
\text { Variáveis } \\
\end{array}$ & Variável & Atributos Necessários/Desejáveis \\
\hline \multirow[t]{4}{*}{$\begin{array}{c}\text { Organizacional } \\
\text { Soft }\end{array}$} & Cultura Organizacional & $\begin{array}{l}\text { Cultura voltada para a melhoria contínua do desempenho da } \\
\text { organização e orientada para os stakeholders, preocupando-se } \\
\text { com a qualidade de vida, ambiente, ética e responsabilidade } \\
\text { social }\end{array}$ \\
\hline & \multirow[t]{2}{*}{ Estilo de Liderança } & $\begin{array}{l}\text { Visível comprometimento da gerência com a estratégia da } \\
\text { organização, no sentido de alocar os necessários recursos no } \\
\text { dia-a-dia, inclusive tempo, com práticas-chave para o sucesso } \\
\text { da estratégia }\end{array}$ \\
\hline & & Liderança tipo coaching \\
\hline & Comunicação Informal & $\begin{array}{l}\text { Ampla e interfuncional, favorecendo constante feedback } \\
\text { sobre as metas, planos de ação e medidas de desempenho }\end{array}$ \\
\hline \multirow[t]{2}{*}{ Tecnologia Hard } & \multirow[t]{2}{*}{ Tecnologia de Informação } & $\begin{array}{l}\text { Sistemas em tempo real, abrangentes e integrados (hardware } \\
\text { e software), com acesso amplo a todos os níveis decisórios }\end{array}$ \\
\hline & & $\begin{array}{l}\text { Sistemas específicos relacionados à operação de uma usina } \\
\text { nuclear }\end{array}$ \\
\hline \multirow[t]{8}{*}{ Tecnologia Soft } & \multirow[t]{4}{*}{ Específicas } & $\begin{array}{l}\text { Metodologias de treinamento, programas e incentivo ao } \\
\text { desenvolvimento de novas soluções com vistas ao } \\
\text { aprimoramento dos processos organizacionais }\end{array}$ \\
\hline & & $\begin{array}{l}\text { Metodologias e técnicas de medição do desempenho global, } \\
\text { setorial e individual, que incluem dimensões quantitativas e } \\
\text { qualitativas de modo balanceado }\end{array}$ \\
\hline & & $\begin{array}{l}\text { Metodologias e técnicas de medição do desempenho global, } \\
\text { setorial e individual, que incluem dimensões quantitativas e } \\
\text { qualitativas de modo balanceado }\end{array}$ \\
\hline & & $\begin{array}{l}\text { Metodologias e técnicas de medição do desempenho global, } \\
\text { setorial e individual, que incluem dimensões quantitativas e } \\
\text { qualitativas de modo balanceado }\end{array}$ \\
\hline & & $\begin{array}{l}\begin{array}{l}\text { Sistemas para prevenção de acidentes nucleares e } \\
\text { planejamento de contingências }\end{array} \\
\end{array}$ \\
\hline & & $\begin{array}{l}\text { Metodologias e técnicas relacionadas à prevenção de } \\
\text { acidentes e a planos de contingência }\end{array}$ \\
\hline & & Metodologias e técnicas de medição dos impactos ambientais \\
\hline & Inovação & $\begin{array}{l}\text { Desenvolvimento de novas medições para indicadores de } \\
\text { grandezas intangíveis, tais como: receptividade e medo da } \\
\text { população e dos empregados em relação aos riscos inerentes } \\
\text { à operação de uma usina nuclear }\end{array}$ \\
\hline \multirow[t]{2}{*}{ Física } & $\begin{array}{l}\text { Equipamentos e Instalações } \\
\text { para Geração de Energia }\end{array}$ & $\begin{array}{l}\text { Instalações e equipamentos que permitam a geração da } \\
\text { energia dentro dos padrões de segurança estabelecidos pelas } \\
\text { agências de fiscalização }\end{array}$ \\
\hline & \begin{tabular}{|l|} 
Laboratórios para \\
Monitoramento Ambiental \\
\end{tabular} & $\begin{array}{l}\text { Laboratórios que permitam realizar o monitoramento do } \\
\text { impacto ambiental causado pela radiação. }\end{array}$ \\
\hline Pessoas & Talentos e Capacidades & $\begin{array}{l}\text { Experiência, habilidades, conhecimento e potencial para } \\
\text { adquirir as necessárias competências para aplicação de novas } \\
\text { metodologias e práticas, que incluem solução de problemas, } \\
\text { melhoria de processos e sistemas de medida balanceados }\end{array}$ \\
\hline Financeira & Caixa - fluxo & $\begin{array}{l}\text { Fluxo de caixa suficiente para garantir liquidez aos } \\
\text { acionistas, mantendo recursos internos para financiar a } \\
\text { manutenção das atividades e o crescimento no longo prazo. }\end{array}$ \\
\hline
\end{tabular}


(conclusão)

Quadro 1: Lista de Atributos Necessários/Desejáveis para as Variáveis Principais Independentes, bem como as Dependentes (Desempenho), no caso da Implementação/Gestão de Estratégia Orientada para os Stakeholders, considerando a Responsabilidade Ética, Social e Ambiental, adaptada para Empresas de Geração de Energia Nucleoelétrica

\begin{tabular}{|l|l|l|}
\hline $\begin{array}{l}\text { Categoria de } \\
\text { Variáveis }\end{array}$ & Variável & Atributos Necessários/Desejáveis \\
\hline $\begin{array}{l}\text { Desempenho } \\
\text { (categoria de } \\
\text { variáveis } \\
\text { dependente) }\end{array}$ & Dimensões Quantitativas & $\begin{array}{l}\text { Margem Operacional Bruta(\%) } \\
\text { Alto retorno para o acionista (ROE), } \\
\text { Liquidez geral, } \\
\text { Custo por MWh Vendido, } \\
\text { Taxa de lucratividade, } \\
\text { Endividamento geral }\end{array}$ \\
& & $\begin{array}{l}\text { Resultados operacionais balizados pelos indicadores da } \\
\text { WANO (World Association of Nuclear Operators) e de } \\
\text { acordo com as metas de produção definidas pela organização }\end{array}$ \\
\cline { 3 - 4 } & Dimensões Qualitativas & Satisfação dos stakeholders \\
\cline { 3 - 4 } & Reputação quanto à responsabilidade social \\
\cline { 3 - 4 } & $\begin{array}{l}\text { Atendimento aos padrões de conduta ética quanto à } \\
\text { preservação ambiental }\end{array}$ \\
\hline
\end{tabular}

Fonte: Figueira e Macedo-Soares, 2003, p. 1181 e Figueira, 2004, p. 62.

\section{Método Analytical Hierarchy Process - AHP}

Uma vez estabelecidas as dimensões de recursos e competências necessárias/ desejáveis para uma empresa de geração de energia nucleoelétrica, cabia também hierarquizá-las em ordem de importância para que ações estratégicas pudessem ser priorizadas e melhor direcionadas. Para tanto, utilizou-se do Analytic Hierarchy Process, AHP, um método de apoio multicritério à decisão, desenvolvido pelo Professor Thomas L. Saaty, na década de 1970. O método foi desenvolvido com base nos fundamentos de Álgebra Linear, Pesquisa Operacional e Psicologia. Seu objetivo primordial é ajudar a escolher uma entre um conjunto de alternativas, a partir de uma série de critérios de priorização. Como vários outros métodos de apoio à decisão, o AHP possui três fases bem distintas: determinar critérios e alternativas relevantes, associar medidas numéricas para mensurar a importância de cada critério e os impactos das alternativas nos critérios e, por fim, processar os valores numéricos para determinar a classificação de cada alternativa (Triantaphyllou, Shu, Nieto Sanchez, \& Ray, 1998).

Em função das críticas ao método AHP clássico e na tentativa de superar algumas de suas limitações, Lootsma (1990) propôs uma variação do método AHP clássico, chamada AHP multiplicativo. Nessa versão, a mudança mais significativa foi a utilização de uma escala geométrica, adotada também nesta pesquisa. 


\section{Metodologia}

O referencial teórico da pesquisa foi estabelecido por meio de extensa revisão da literatura na área de gestão estratégica, assim como por um levantamento de trabalhos que tratavam de estratégias competitivas e modelos de gestão para o setor elétrico brasileiro.

A avaliação estratégica foi conduzida no âmbito de um estudo de caso da empresa Eletronuclear. Esse método foi adotado, porque a análise dizia respeito a um fenômeno contemporâneo, precisamente à estratégia atual da referida empresa, a qual só podia ser investigada no âmbito do seu contexto real. De acordo com Yin (2001), foram utilizados múltiplos meios de investigação: documental/ telematizada e dois levantamentos de percepções: i) um levantamento das percepções da alta gerência, com auxílio de formulário estruturado, preenchido por ocasião das entrevistas dos principais executivos da empresa; ii) levantamento complementar com auxílio de questionário estruturado, enviado a todos os gerentes da Eletronuclear. A triangulação dos métodos, ou seja, a utilização de vários meios e fontes, visando à coleta de dados sobre fenômenos semelhantes, permitiu superar grande parte das limitações inerentes a cada um dos métodos.

Embora o estudo de caso enfocasse a empresa Eletronuclear, procurou-se enriquecer os resultados da pesquisa, agregando informações sobre outras empresas geradoras de energia. Para tanto realizou-se uma investigação documental/telematizada dos recursos e competências de duas outras geradoras de energia no Brasil, Chesf e Furnas, além de duas geradoras de energia nucleoelétrica internacionais, a americana Exelon e a finlandesa Tvo.

Para promover o levantamento de percepções dos principais executivos da empresa acerca do painel de competências, constituído a partir do arcabouço proposto no modelo GI, elaborou-se um formulário (preenchido pelo pesquisador), com base nos construtos e indicadores estabelecidos no referencial teórico, constituído por perguntas fechadas, com formato Likert (escala 1 a 5), e ainda perguntas abertas para obtenção de respostas livres obtidas no âmbito da entrevista.

Os dados levantados, por meio da investigação documental/telematizada e do levantamento de percepções, foram preparados para a etapa subseqüente: a análise de conteúdo (Morse, 1994; Weber, 1990). Assim, classificaram-se os dados em oito categorias de conteúdo, gerando variáveis válidas que representassem os constructos que se pretendia medir, conforme Quadro 1.

Para a identificação das implicações estratégicas dos fatores organizacionais pertencentes à principal empresa em estudo, cotejaram-se os dados levantados 
com os atributos e indicadores apresentados no referencial teórico. Dessa comparação surgiu um painel de recursos e competências necessários e desejáveis para a gestão da geração de energia nucleoelétrica no Brasil. Para hierarquizálos, promoveu-se o segundo levantamento de percepções, por meio do questionário estruturado segundo o método AHP.

Em seguida, os dados foram validados quanto à completude e coerência, com vistas a eliminar os questionários com respostas inconsistentes. Na seqüência, os dados foram trabalhados segundo a metodologia do AHP, produzindo as classificações e os devidos índices de consistência, de modo a permitir a desejada hierarquização das competências, segundo o grau de importância.

\section{REsultados}

A seguir, os resultados da análise estratégica da Eletronuclear são apresentados, de acordo com os passos descritos na introdução.

\section{Caracterização da Estratégia}

Com relação à caracterização da estratégia da empresa, verificou-se que, segundo a visão declarada em seu site eletrônico, a Eletronuclear vê-se como: "Uma empresa reconhecida pela excelência de seu desempenho, comprometida com a melhoria da qualidade de vida da população, gerando uma energia limpa, a partir de um combustível abundante no país e mantendo-se na vanguarda tecnológica". De acordo com essa visão, a missão da empresa é: "Projetar, construir e operar usinas nucleares com alta segurança e eficiência, atendendo às necessidades do sistema, através da produção de energia elétrica com custos competitivos". Em síntese, trata-se de uma estratégia explícita de diferenciação por qualidade, na busca da excelência orientada para os stakeholders.

No que concerne ao seu escopo estratégico, a pesquisa documental/telematizada forneceu as seguintes informações, classificadas de acordo com os constructos de Fahey e Randall (1998): i) produto : energia nucleoelétrica; ii) cliente : Furnas; iii) escopo geográfico: sistema interligado, isto é, conjunto de redes de distribuição interligadas que atende às regiões Sul, Sudeste, Centro-Oeste, Nordeste e parte da região Norte; iv) escopo vertical: a empresa só atua na geração da energia; v) stakeholders: Eletrobrás, dona de $99,54 \%$ do capital social e principal credora da empresa; governos federal, estadual e municipal, devido aos impostos arrecadados; fornecedores de equipamentos pesados nacionais e internacionais; fornecedor de urânio enriquecido; Furnas, principal cliente; empregados da Eletronuclear e a sociedade como um todo. 


\section{Implicações Estratégicas dos Fatores Macroambientais e dos Atores-chave}

Ainda com base na pesquisa documental/telematizada, ficou bastante nítida a implicação negativa do atraso na definição do modelo econômico do setor elétrico brasileiro. É o caso, em especial, da não regulamentação da tarifa aplicável à energia nucleoelétrica, uma vez que, sem tarifa que cubra seus custos operacionais, a Eletronuclear tem registrado perda considerável de receita, além de estar atrasando novos investimentos em Angra III e inviabilizando o retorno do investimento de um de seus stakeholders, a Eletrobrás.

No que concerne às implicações estratégicas dos outros fatores econômicos, a análise revelou que há mais oportunidades potenciais do que ameaças, uma vez que há demanda por outras fontes de energia, que não a hidráulica. O que torna essa oportunidade ainda mais relevante para uma empresa como a Eletronuclear é já existir toda uma infra-estrutura tecnológica e de distribuição para escoar a energia nucleoelétrica produzida, tendo em vista que Angra dos Reis fica bem próxima aos grandes centros consumidores de energia do país: $130 \mathrm{~km}$ do Rio de Janeiro, 220 km de São Paulo e 350 km de Belo Horizonte. Ademais, o Brasil possui a sexta maior reserva de urânio do planeta, aumentando ainda mais a vantagem em relação ao gás e ao óleo diesel, que são importados e estão sujeitos à volatilidade de preços das moedas estrangeiras. Há também que se considerar outro fator econômico relevante: o grau de economicidade, uma vez que os combustíveis, como carvão, óleo diesel e gás natural produzem menos energia, quando comparados à mesma quantidade de urânio.

Por outro lado, a análise dos fatores socioculturais evidenciou que há preocupações da sociedade com relação à utilização da energia nucleoelétrica, em face das consequiências destrutivas que um acidente causaria não só para o meio-ambiente, como também para a população das cidades próximas, como os que ocorreram em Goiânia (1987), Chernobyl na Rússia (1986) e Three Miles Island nos Estados Unidos (1979). Considerando esse receio coletivo, classificouse a imagem negativa associada à energia nucleoelétrica como ameaça real.

Para analisar as implicações estratégicas das diferentes fontes de energia elétrica, consideraram-se as usinas térmicas a gás, a eólica, a solar, a biomassa e as pequenas centrais hidrelétricas como novos entrantes. Foram assim considerados em função do número reduzido de unidades desse tipo e também por serem tecnologias mais recentes no Brasil. Já as usinas térmicas movidas a óleo diesel/ derivados do petróleo ou carvão mineral, e as hidrelétricas convencionais, por já serem componentes expressivos da matriz energética, foram consideradas como fontes substitutas. 
Cabe notar que, após a assinatura do Protocolo de Kioto, em dezembro de 1997, a exploração da energia nuclear, para fins não destrutivos, tem-se caracterizado como exemplo de desenvolvimento sustentável, em comparação a outros combustíveis fósseis, tais como óleo diesel e carvão, que liberam grande quantidade de gases nocivos ao meio-ambiente. Em relação à energia hidráulica, também se verifica certa vantagem da energia nucleoelétrica, em virtude dos danos ambientais que, em geral, uma usina hidrelétrica acarreta. Em função disso, o uso da tecnologia nuclear surge como oportunidade real, quando comparada às fontes substitutas.

Quanto aos novos entrantes, a pesquisa constatou certa ambigüidade. Em termos ambientais, os impactos de usinas eólicas, solares, de biomassa e de pequenas centrais hidrelétricas são menores do que uma usina nuclear que, embora não polua o meio ambiente, produz rejeitos radioativos. Por outro lado, como ainda não há unanimidade entre os ambientalistas com relação ao uso dessas fontes de energia alternativas e seus possíveis efeitos danosos, essas fontes foram consideradas tanto como oportunidade quanto ameaça, ambas potenciais, em comparação com a energia nucleoelétrica. Especificamente em relação ao gás, combustível de algumas modalidades de usinas térmicas, se a exploração for viável economicamente, o preço do gás deverá ficar mais baixo, representando, assim, uma forte ameaça potencial.

Tanto os fornecedores de insumos de bens e equipamentos quanto os fornecedores de urânio enriquecido foram identificados como ameaça real. Em primeiro lugar, porque, além de imprescindíveis para o negócio, não existem muitas alternativas de fornecedores no mundo inteiro. Ademais, é preciso importar boa parte desses insumos, indexados à variação de moedas fortes como o euro e o dólar americano.

A única cliente, Furnas, constitui uma ameaça real, porque, ao vender segundo um modelo monopolista, com tarifa regulada e previamente contratada, ela não permite receber pelo preço do mercado a vista. Por outro lado, trata-se também de uma oportunidade potencial, porquanto os contratos atuais garantem que a energia gerada seja vendida, mesmo em momentos de excesso de oferta no mercado.

Tendo em vista que o ciclo operacional de funcionamento de uma usina nuclear acarreta a parada para a troca do combustível, por alguns dias, uma vez por ano, uma das alternativas, identificada como viável para suprir o período de reabastecimento de combustível, foi o estabelecimento de acordos com outras usinas. Assim, tanto as usinas hidrelétricas convencionais quanto as usinas térmicas foram classificadas como complementadoras e consideradas como oportunidades potenciais. 
O estudo confirmou, outrossim, que o apoio e o interesse das Prefeituras próximas a Angra dos Reis puderam ser caracterizados como oportunidades reais. A única ameaça real identificada foi a ANEEL, tendo em vista sua incapacidade de regular os assuntos relacionados à energia nucleoelétrica. Entretanto, uma vez resolvida essa questão, o órgão regulador deve constituir-se em uma oportunidade potencial, na medida em que poderá assegurar o equilíbrio econômicofinanceiro da empresa.

\section{Implicações Estratégicas dos Fatores Organizacionais}

Em consonância com o referencial teórico, na análise dos fatores organizacionais, estabeleceu-se uma distinção entre os tipos de competências: necessária ou desejável. Adicionalmente, cada fator foi classificado como força ou fraqueza, real ou potencial.

Com base principalmente nos levantamentos de percepções, a análise evidenciou que as principais forças da empresa estão concentradas na dimensão tecnológica, tanto nos aspectos tangíveis quanto nos intangíveis. Atualmente, a Eletronuclear domina as fases de projeto, construção e operação das usinas, além de já ter incorporado o conhecimento de cerca de $90 \%$ dos sistemas de gerenciamento da usina, o que constitui uma competência que foi considerada como necessária.

Outra força identificada foi a localização física de Angra dos Reis, que oferece condições meteorológicas favoráveis e abundância de água do mar para refrigeração dos condensadores de vapor das usinas. Assim, a localização foi considerada um recurso desejável.

Na dimensão organizacional, a pesquisa destacou como força real o histórico da empresa na capacitação de seu corpo técnico e a implantação de uma sistemática de gestão do conhecimento. Ademais, evidenciou uma intenção clara de descentralizar o poder decisório da empresa como meio de torná-la menos burocratizada e mais flexível. O problema era a cultura organizacional. Por manter traços de organização tipicamente estatal, com modelo de administração ainda pouco participativo e estrutura organizacional relativamente hierarquizada (cinco níveis), ela foi considerada fraqueza real.

Na dimensão financeira, a pesquisa também identificou uma fraqueza real, porque, segundo o modelo setorial vigente, a energia gerada pela Eletronuclear não pode ser comercializada livremente e sua tarifa depende de regulamentação da ANEEL.

Com relação às condições necessárias para o aproveitamento dos recursos e competências da empresa, os resultados da pesquisa revelaram dificuldades 
também nas dimensões financeira e organizacional. Das fraquezas reais identificadas destacaram-se: i) a falta de consistência entre os objetivos e metas contidos no planejamento estratégico e o sistema de avaliação de desempenho da organização e dos funcionários, por não incluir nele indicadores pertinentes a todos os stakeholders; ii) as dificuldades de mudança na cultura organizacional; iii) a falta de clareza na comunicação dos objetivos estratégicos da corporação. Além disso, verificou-se que a interferência do Estado, principal acionista, pode prejudicar questões ligadas à remuneração e à sistemática de avaliação do desempenho.

\section{Desempenho Organizacional}

A pesquisa identificou que o desempenho financeiro da empresa, avaliado segundo indicadores como liquidez corrente, margem operacional bruta e outros, está muito aquém do que deveria ocorrer para uma empresa que pretende ampliar suas atividades, construindo até mais uma usina. Quando comparada com Furnas e Chesf, a margem operacional bruta (em \%) e o custo por MWh vendido denunciam também as dificuldades financeiras da empresa mencionadas anteriormente. Ainda se verificou que, embora a Eletronuclear tenha uma estratégia voltada para seus stakeholders, a Eletrobrás, principal acionista, não vem recebendo o retorno dos seus investimentos.

Por sua vez, com relação ao desempenho operacional, os dados levantados demonstram que a Eletronuclear vem atingindo as metas preestabelecidas pelo planejamento estratégico e que ela opera dentro dos padrões de referência da WANO (World Association of Nuclear Operators). Ficou evidente também que a empresa atribui grande importância a outras variáveis de cunho operacional, tais como grau de inovação e índices relacionados à preservação ambiental. Para garantir o cumprimento dos termos do licenciamento ambiental que lhe foi concedido, a Eletronuclear mantém laboratórios de monitoração ambiental, nos quais se executam programas de controle ambiental, cumprindo as exigências dos órgãos fiscalizadores nacionais e internacionais. Além disso, o grande número de campanhas assistenciais e educacionais voltadas à comunidade evidenciaram uma preocupação acentuada com a segurança das pessoas que trabalham e moram perto da usina.

Por outro lado, ao analisar a dimensão qualitativa do desempenho, não foi possível comprovar a existência de indicadores qualitativos que atestem o compromisso da empresa com a preservação ambiental e com a responsabilidade ética e social, embora os documentos oficiais pesquisados contivessem indícios claros dessa intenção. 


\section{Recursos e Competências de Outras Geradoras}

Como planejado, a pesquisa procurou levantar, em duas geradoras nacionais, Chesf e Furnas, e em duas geradoras internacionais, Exelon e Tvo, recursos e competências que não existiam, ou que não tinham sido desenvolvidos completamente na Eletronuclear. Os resultados obtidos, validados pelos gestores da organização, demonstram que há oportunidades de melhoria no que concerne aos recursos/competências da empresa (Quadro 2).

\section{Quadro 2: Recursos e Competências de Outras Geradoras que Podem ser Desenvolvidos na Eletronuclear}

\begin{tabular}{|c|c|}
\hline Categoria de Variáveis/Variáveis & Atributos necessários/desejáveis \\
\hline \multicolumn{2}{|l|}{ Organizacional Hard } \\
\hline $\begin{array}{l}\text { Sistemas de Medição de } \\
\text { Desempenho }\end{array}$ & $\begin{array}{l}\text { Além dos atributos relacionados na Quadro } 1 \text {, os sistemas devem } \\
\text { contemplar indicadores de responsabilidade social, econômica e } \\
\text { ambiental. }\end{array}$ \\
\hline Sistemas de Auditoria & $\begin{array}{l}\text { Amplos, consistentes e aderentes aos sistemas de avaliação de } \\
\text { desempenho, de modo a validar os processos de negócio da organização e } \\
\text { os indicadores de desempenho apurados em todos os níveis. }\end{array}$ \\
\hline \multicolumn{2}{|l|}{ Tecnologia Hard } \\
\hline \multirow[t]{2}{*}{ Tecnologias de Informação } & $\begin{array}{l}\text { Sistemas específicos relacionados à operação de uma usina nuclear que } \\
\text { priorizem a segurança da população e dos empregados envolvidos no } \\
\text { processo, bem como o cuidado com o meio-ambiente. }\end{array}$ \\
\hline & $\begin{array}{l}\text { Sistema de gestão ambiental, contendo todos os indicadores relacionados } \\
\text { ao meio-ambiente e meios para acompanhar sua realização. }\end{array}$ \\
\hline \multicolumn{2}{|l|}{ Tecnologia Soft } \\
\hline $\begin{array}{l}\text { Tecnologias para melhoria da } \\
\text { eficiência energética }\end{array}$ & $\begin{array}{l}\text { Programas de eficiência energética que permitam melhorar o rendimento } \\
\text { das atuais usinas, aumentando a oferta de energia sem necessitar construir } \\
\text { novas plantas nucleares. }\end{array}$ \\
\hline $\begin{array}{l}\text { Metodologias e técnicas específicas } \\
\text { para exploração de outras fontes de } \\
\text { energia }\end{array}$ & $\begin{array}{l}\text { Tecnologia para exploração de outras fontes de energia, buscando } \\
\text { principalmente fontes renováveis e não-poluentes. }\end{array}$ \\
\hline \multicolumn{2}{|l|}{ Física } \\
\hline $\begin{array}{l}\text { Equipamentos e instalações para } \\
\text { exploração de outras fontes de } \\
\text { energia }\end{array}$ & $\begin{array}{l}\text { Instalações e equipamentos que permitam a exploração de outras fontes } \\
\text { de energia, buscando principalmente fontes renováveis e não-poluentes. }\end{array}$ \\
\hline $\begin{array}{l}\text { Instalações para armazenamento de } \\
\text { combustível e rejeitos sólidos }\end{array}$ & $\begin{array}{l}\text { A geração de energia nucleoelétrica requer um local para armazenamento } \\
\text { do combustível e também dos rejeitos gerados. Em ambos os casos, hão } \\
\text { que se estabelecer rígidas normas de segurança e cuidados com o meio- } \\
\text { ambiente. }\end{array}$ \\
\hline \multicolumn{2}{|l|}{ Pessoas } \\
\hline Renovação do quadro de pessoal & $\begin{array}{l}\text { Equipes formadas por profissionais mais experientes e alguns recém- } \\
\text { saídos do meio acadêmico que podem criar uma ambiente propício à } \\
\text { inovação, à motivação e principalmente à preservação do expertise na } \\
\text { tecnologia nuclear. }\end{array}$ \\
\hline \multicolumn{2}{|l|}{ Financeira } \\
\hline $\begin{array}{l}\text { Racionalização de recursos } \\
\text { financeiros }\end{array}$ & $\begin{array}{l}\text { Um programa eficiente de redução de custos que procure melhorar as } \\
\text { margens operacionais e atender a todos os stakeholders, poderá contribuir } \\
\text { para a saúde financeira da organização. }\end{array}$ \\
\hline Novos negócios & $\begin{array}{l}\text { Uma das alternativas para sobreviver em um mercado competitivo, no } \\
\text { qual os recursos são escassos e cada vez mais disputados, é buscar } \\
\text { alternativas de novos negócios com as competências da própria } \\
\text { organização. }\end{array}$ \\
\hline
\end{tabular}




\section{Priorização de Categorias de Recursos e Competências}

Definidas as variáveis integrantes de cada dimensão de recursos e competências, a priorização, por ordem de importância para a estratégia da empresa, foi estabelecida pelos gestores da organização, com apoio de um questionário desenvolvido segundo o método AHP. Saaty (1990) recomenda o cálculo de um índice de consistência a partir do resultado da priorização obtida, como meio de validar a consistência das comparações feitas. O mesmo autor recomenda que tal índice não deve superar o valor de 0,1 . No caso em exame, o resultado consolidado apontou um índice de consistência de 0,02 , que confirma a consistência dos dados coletados. Os resultados ratificaram os da pesquisa documental e do levantamento de percepções, ao revelar que a maioria dos gerentes priorizou as dimensões financeira, organizacional hard e pessoas, como as que requerem maior atenção da gestão da empresa. Em termos percentuais, as dimensões obtiveram a seguinte pontuação: financeira $(24,52 \%)$, organizacional hard $(18,06 \%)$, pessoas $(17,89 \%)$, organizacional soft $(14,95 \%)$, física $(8,63 \%)$, tecnologia hard $(8,48 \%)$ e tecnologia soft $(7,47 \%)$.

\section{Análise da Adequação Estratégica}

Ao identificar pontos fracos, a análise estratégica salientou as inconsistências da atual estratégia da Eletronuclear.

A análise dos fatores macroambientais econômicos revelou que, mesmo dentro de um cenário repleto de incertezas, o atual contexto do país oferece oportunidades para empresas geradoras; a questão é decidir qual fonte de energia é a mais adequada. As principais variáveis envolvidas na escolha estão relacionadas ao custo por MWh gerado e aos impactos ambientais decorrentes da instalação e operação.

Embora a energia nucleoelétrica requeira investimentos vultosos e tenha um custo de geração relativamente alto, os impactos ambientais reduzidos tornam essa energia uma alternativa viável para atender à demanda do mercado que deverá crescer muito nos próximos anos. Entretanto o fraco desempenho econômico e os escassos recursos financeiros, ambos classificados como fraquezas reais, representam um impasse para a realização de novos investimentos, o que dificulta a manutenção das instalações existentes, dentro dos padrões de segurança exigidos e a ampliação da capacidade produtiva.

Os resultados da análise dos fatores organizacionais sugerem haver uma relação entre as forças da dimensão tecnológica e da dimensão pessoas com o bom desempenho operacional das usinas. No entanto também sugerem que as forças 
da empresa estão sucumbindo às fraquezas e não estão conseguindo neutralizar as ameaças provenientes do macroambiente político e do ator Governo. Em conseqüência, a Eletronuclear não tem sido capaz de aproveitar as oportunidades oferecidas pelo macroambiente, no sentido de aumentar a oferta de energia no mercado, uma vez que não detém recursos financeiros suficientes para novos investimentos. Ao comparar as competências e condições organizacionais existentes com as necessárias e desejáveis, verifica-se a existência de três fraquezas reais interligadas: a cultura organizacional - tipicamente estatal, o modelo de administração pouco participativo e a estrutura organizacional - pouco flexível e muito centralizada.

Em suma, a análise da adequação estratégica da Eletronuclear evidenciou que, embora a empresa tenha forças reais significativas nas dimensões física e tecnológica, bem como força potencial na dimensão pessoas, as fraquezas evidenciadas nas dimensões organizacional e financeira, aliadas às ameaças criadas pelo macroambiente (fatores político-econômicos) e pelo ator Governo, não estão permitindo que a empresa capitalize suas forças, a fim de melhor aproveitar as oportunidades decorrentes do macroambiente, principalmente dos fatores econômicos e dos atores-chave.

\section{Discussão e Considerações Finais}

Por meio da análise estratégica, cujos resultados foram apresentados na seção anterior, a pesquisa verificou que a Eletronuclear detém um conjunto de recursos e competências valiosos que, no entanto, se vem deteriorando nos últimos três anos.

Dentre os resultados mais significativos da pesquisa cabe destacar a inconsistência entre a estratégia declarada pela empresa e a que vem sendo adotada, em função das ameaças constituídas pelos fatores macroambientais (fatores político-econômicos) e pelo ator Governo, o que paulatinamente vem minando as forças reais constituídas pelo valioso ativo intelectual e pela tecnologia de ponta. A pesquisa enfatizou ainda que a atual inconsistência não é uma questão recente. Pelo contrário, a empresa vem sofrendo, há três anos, as conseqüências de uma indefinição em relação ao modelo de comercialização da energia nucleoelétrica e gastando, anualmente, cerca de 20 milhões de dólares para manter os equipamentos comprados para a usina de Angra 3, em face da indefinição sobre a construção da usina.

Ainda que grande parte das ameaças seja proveniente do ambiente externo, a pesquisa evidenciou que alguns fatores organizacionais integrantes do arcabouço 
analítico proposto podem ser aprimorados, a fim de assegurar à empresa uma estrutura interna sólida e organizada de tal modo que as ameaças externas, como as que a empresa hoje enfrenta, possam ser amortecidas e superadas sem desestabilizar a organização.

Nesse sentido, recomenda-se o aprimoramento na atual estrutura organizacional considerada muito hierarquizada; a adoção de sistemas de medição de desempenho alinhados aos objetivos estratégicos da companhia; a revisão dos processos de reconhecimento e recompensa e sua integração ao sistema de avaliação de desempenho global da organização; a utilização de modelos de gestão mais participativos que incentivem a atuação multidisciplinar e permitam, aos poucos, trabalhar melhor a cultura organizacional caracterizada como tipicamente estatal; a realização de ciclos periódicos de planejamento estratégico, com processo regular de acompanhamento e feedback dos resultados alcançados.

Ao término da pesquisa, pode-se afirmar que seu objetivo principal foi alcançado, ou seja, não somente chegou-se a um arcabouço analítico composto por recursos e competências considerados indispensáveis a uma gestão estratégica mais efetiva da geração de energia nucleoelétrica no Brasil (Quadro 1), mas também se verificou que, em outras empresas geradoras, existiam recursos e competências não disponíveis ou não desenvolvidos plenamente na Eletronuclear e que podiam ser agregados à organização (Quadro 2).

Em realidade, a pesquisa foi além do objetivo inicial estabelecido. Por meio da análise estratégica realizada, confirmou-se o grande dilema institucional que a organização atravessa atualmente e que pode até mesmo colocar em risco sua própria continuidade. Paradoxalmente, as inconsistências estratégicas identificadas na análise ajudaram na construção do arcabouço analítico de recursos e competências, uma vez que evidenciaram quais fatores organizacionais requeriam mais ênfase da direção da empresa, com vistas a viabilizar os objetivos estratégicos da Eletronuclear e quais podiam ser agregados de outras geradoras nacionais e internacionais. O resultado da priorização, estabelecida por meio do método AHP, ratificou a importância atribuída às dimensões financeira e organizacional, tal como já havia sido apurado nos levantamentos de percepções.

Como continuidade deste estudo, sugere-se, inicialmente, a extensão do método AHP para comparar recursos e competências de cada dimensão do modelo GI, com vistas a aprimorar o resultado obtido e permitir uma ação mais direta com relação aos recursos e às competências que devem ser priorizados na gestão da empresa. Além disso, no setor de energia nucleoelétrica, seria recomendável estudar mais extensamente a experiência de outros países que também utilizam a energia nucleoelétrica em sua matriz energética. Tal estudo poderia trazer novas luzes acerca de problemas que, aparentemente, o Brasil ainda não equacionou, 
tais como: os depósitos para rejeitos sólidos produzidos pelas usinas, o fundo para descomissionamento e o modelo de comercialização aplicável à energia nucleoelétrica.

De maneira geral, análises estratégicas serão sempre bem-vindas ao setor elétrico, porque, muito embora seja um setor no qual as oportunidades surgem com rapidez, ainda há grandes transformações a ocorrer. Especificamente, a área de energias renováveis (eólicas, biomassa, solar e outras), que parece despontar como alternativa viável para o Brasil, requer toda uma infra-estrutura de recursos e competências organizacionais; entretanto não foram ainda adequadamente pesquisados.

\section{Artigo recebido em 25.01.2005. Aprovado em 13.06.2005.}

\section{ReferênCIAS BibliográficAs}

Austin, J. E. (1990).

Managing in developing countries: strategic analysis and operating techniques. New York: The Free Press.

Brandenburger, A. M., \&

Nalebuff, B. J. (1997).

Co-opetition: a revolution mindset that combines competion and cooperation: the game theory strategy that's changing the game of business. New York: Doubleday.

Cherns, A. B. (1976).

The principles of socio-technical design. Human Relations, 29(8), 783792.

\section{Child, J. (1987).}

Organizational design for advanced manufacturing technology. In T. D. Wall, C. W. Clegg, \& N. J. Kemp (Eds.). The human side of advanced manufacturing technology. New York: Ed. John Wiley.
Coutinho, R., \&

Macedo-Soares, T. D. L. A. v. (2002). Gestão estratégica com responsabilidade social: arcabouço analítico para auxiliar sua implementação em empresas no Brasil. Revista de Administração Contemporânea, 6(3), 75-96.

Day, G. S.,

Reibstein, D. J., \&

Gunther, R. (1997).

Wharton on dynamic competitive strategy. U.S.A.: John Wiley \& Sons.

Diericks, I., \&

Cool, K. (1989).

Asset stock accumulation and sustainability of competitive advantage. Management Science, 35(12), 1504-1511.

Fahey, L., \&

Randall, R. M. (1998).

Learning from the future. New York: John Wiley. 
Figueira, L. A. P. A. (2004).

Estratégias para geração de energia nucleoelétrica no Brasil. Dissertação de Mestrado, Pontifícia Universidade Católica do Rio de Janeiro, RJ, Brasil.

Figueira, L. A. P. A., \&

Macedo-Soares, T. D. L. A. v. (2003).

Estratégia de geração de energia nuclear no Brasil - O caso da Eletronuclear. Revista de Administração Pública, 37(6), 1171-1195.

Grant, R. M. (1998).

Contemporary strategy analysis: concepts, techniques, applications. Oxford: Blackwell Publishers.

Hofer, C., \&

Schendel, D. E. (1978).

Strategy formulation. St. Paul, MN:

West Publishing.

Lootsma, F. A. (1990).

The french and the american schools in muti-criteria decision analysis. Operations Research, 24(3), 263-285

Macedo-Soares, T. D. L. A. v. (2000). An integrative model for strategic management analysis: application to organizations in Brazil. Proceedings of INFORMS-KORMS Conference, Seoul, Korea.

Macedo-Soares, T. D. L. A. v., \& Chamone, S. G. (1994).

Total quality strategies in industry. Quality Management Journal, 1(3), 57-79.

Macedo-Soares, T. D. L. A. v., \& Lucas, D. C. (1996).

Práticas gerenciais de qualidade das empresas líderes no Brasil. Rio de Janeiro: Qualitymark.
Macedo-Soares, T. D. L. A. v., \&

Ratton, C. (1999).

Medição de desempenho e estratégias orientadas para o cliente: resultados de uma pesquisa de empresas líderes no Brasil. Revista de Administração de Empresas, 39(4), 46-59.

Mintzberg, H. (1998).

Generic strategies: toward a comprehensive framework. Advances in Strategic Management, 5, 1-67.

Morse, J. M. (1994).

Critical issues in qualitative research methods. London: SAGE.

Nadler, D. A.,

Gerstein, M. S.,

Shaw, R. B., \&

Associates. (1992).

Organizational architecture: designs for changing organizations. San Francisco: Jossey-Bass Publishers.

Porter, M. E. (1980).

Competitive strategy: techniques for analyzing industries and competitors. New York: Free Press.

Rumelt, R. P.,

Schendel, D., \&

Teece, D. (1991).

Strategic management and economics. Strategic Management Journal, 12(1), 5-30.

Ssaty, T. L. (1990).

Decision making for leaders: the analytic hierarchy process for decisions in a complex world. Pittsburg: RWS Publications. 
Sjölander, S. (1985).

Early stage management of innovation. Tese de Doutorado, Chalmers University of Technology, Göteborg, Sweden.

Teece, D. J.,

Pisano G., \&

Shuen, A. (1997).

Dynamic capabilities and strategic management. Strategic Management Journal, 18(7), 509-534.

Triantaphyllou, E.,

Shu, B.,

Nieto Sanchez, S., \&

Ray, T. (1998).

Multi-criteria decision making: An operations research approach. In J. G. Webster (Ed.). Encyclopedia of electrical and electronics engineering. (Vol. 15, pp. 175-186). New York, NY: John Wiley \& Sons.

Van der Heijden, K. (1996).

Scenarios. New York: John Wiley \& Sons.
Vollmann, T.E. (1996).

The transformation imperative: achieving market dominance through radical change. Boston, MA: Harvard Business Scholl Press.

Weber, R. P. (1990).

Basic content analysis. Newbury Park, CA: Sage Publications.

Wernerfelt, B. A. (1984).

A resource-based view of the firm. Strategic Management Journal, 5(2), 171-180.

Yin, R. K. (2001).

Estudo de caso: planejamento e métodos (2a ed.). Porto Alegre: Bookman.

Zollo, M., \&

Winter, G. S. (2002).

Deliberate learning and the evolution of dynamic capabilities. Organization Science, 13(3), 339-351. 